\title{
A combination of cellular biomarkers predicts failure to respond to rituximab in rheumatoid arthritis: a 24-week observational study
}

Martin H. Stradner, Christian Dejaco, Kerstin Brickmann, Winfried B. Graninger and Hans Peter Brezinschek (D)

\begin{abstract}
Background: Although B cell depletion with rituximab (RTX) is an effective treatment strategy in rheumatoid arthritis (RA), one third of patients do not achieve remission or low disease activity (LDA). Thus, identifying patients who will benefit from RTX is highly desirable. In the present study we investigated whether lymphocyte subsets other than B cells are predictors of a clinical response to RTX treatment.

Methods: Patients with RA who were receiving RTX for the first time were included in an observatory registry. Clinical assessments, complete blood count and flow cytometry of lymphocyte subsets were obtained at baseline and at week 24 after RTX. Complete data were available for 44 patients. Logistic regression and receiver operating characteristic curve analyses were computed to analyze the predictive value of lymphocyte subsets for European League Against Rheumatism (EULAR) response and LDA (defined as disease activity score in 28 joints (DAS28) $\leq 3.2$ ) at week 24.

Results: EULAR responders had lower total lymphocyte counts (LC), T cells and CD4 + T cells at baseline. Although these parameters were independent predictors of EULAR response they failed in determining who would reach LDA. In contrast, LC $>2910 / \mu$ or plasmablast frequency $>2.85 \%$ at baseline predicted a significantly higher DAS28 at week 24 after RTX and identified patients not achieving LDA at week 24 with sensitivity of $93.3 \%$ and specificity of $44.8 \%$.
\end{abstract}

Conclusions: A combination of LC and plasmablast frequency identifies patients with RA who will not benefit from RTX with high probability.

Keywords: Rheumatoid arthritis, Biomarker, Rituximab, T cells, Plasmablasts, Lymphocytes

Abbreviations: ACPA, anti-citrullinated peptide antibodies; ACR, American College of Rheumatology; ANOVA, analysis of variance; bDMRD, biologic disease-modifying anti-rheumatic drug; BL, baseline; DAS28, disease activity score 28; EULAR, European League Against Rheumatism; hiLOP, high number of total lymphocyte count or plasmablasts; LC, total lymphocyte counts; LDA, low disease activity; loLAP, low number of total lymphocyte count and plasmablasts; RA, rheumatoid arthritis; RF, rheumatoid factor; RTX, rituximab; TNF, tumor necrosis factor

\footnotetext{
* Correspondence: hans-peter.brezinsek@medunigraz.at

Division of Rheumatology and Immunology, Medical University of Graz, Graz, Austria
} 


\section{Background}

With the introduction of biologic disease-modifying anti-rheumatic drugs (DMARDs) (bDMRDs) the armamentarium to fight rheumatoid arthritis (RA) has been dramatically enlarged [1]. However, we are unable to predict which of these therapies would be optimal for a certain patient. For example, B cell depletion with the chimeric monoclonal antibody rituximab (RTX) is an effective treatment strategy for RA. However, a considerable proportion of around $30 \%$ of patients with RA treated with RTX fail to respond, particularly after previous therapy with tumor necrosis factor (TNF)- $\alpha$ inhibitors [2]. Identification of patients likely to respond to RTX treatment would result in an optimized treatment strategy reducing unnecessary socio-economic costs and potential side effects. Currently available clinical and laboratory parameters predicting the success of RTX therapy include the presence of rheumatoid factor (RF) and/or anti-citrullinated peptide antibodies (ACPA), and the absence of current glucocorticoid therapy [3-5]. In addition, high serum calprotectin has been associated with good or moderate response to RTX [6]. Furthermore, several authors have demonstrated that patients with RA who have a high frequency of plasmablasts are less likely to respond to RTX [7-11].

All these factors, however, have been established to predict EULAR response. Current recommendations for the treatment of RA define remission or low disease activity (LDA) in patients with long-standing disease as the goal of treatment after 6 months [12], a target that is not achieved with a moderate EULAR response in many cases.

Whether factors other than B cell subsets or their products might help us to find the optimal therapy for a particular patient is still unknown. As several immune competent cells are involved in the pathogenesis of RA [13] the efficacy of a certain bDMARD might be determined not only by its defined target but also by cells or molecules interacting with it. Thus, the influence of RTX on T cells became an alternative focus of recent investigations [14-16].

In the present study, we analyzed 1) whether baseline levels of lymphocyte subsets other than those of B cells may predict clinical response to RTX and 2) whether changes in $\mathrm{T}$ cell subsets correlate with clinical outcomes.

\section{Methods \\ Patients}

Data from the Austrian Rituximab registry were used for this study. The clinical protocol with a detailed description of inclusion and exclusion criteria, interventions, and clinical and laboratory assessments has been described earlier [11]. Briefly, consecutive patients were included who fulfilled the 1987 American College of Rheumatology
(ACR) classification criteria for RA [17] and were receiving RTX for the first time. All patients received 1000 mg RTX preceded by the administration of $100 \mathrm{mg}$ of prednisolone at baseline and after 2 weeks. Complete blood count, lymphocyte analysis, and assessment of disease activity score in 28 joints (DAS28) using the erythrocyte sedimentation rate were carried out before RTX treatment and at week 24. Patients were classified according to European League Against Rheumatism (EULAR) as good responders, moderate responders, or non-responders [18]. LDA was defined as a DAS28 $\leq 3.2[19]$.

\section{Lymphocyte analysis}

Blood cell counts in peripheral blood samples were obtained using a Beckman Coulter HMX hematology analyzer (Beckman Coulter, Miami, FL, USA). For determination of lymphocyte subsets whole blood was stained for CD45, CD3, CD19, CD4, CD8, CD56, and CD16 using the BD Multitest IMK kit (Becton Dickinson, Heidelberg, Germany). After fixation and erythrocyte lysis according to the manufacturer's protocol, cells were analyzed on a FACS Calibur flow cytometer (Becton Dickinson) using FACS Diva software (Becton Dickinson).

\section{Statistical analysis}

All statistical analyses were performed using the SPSS program, version 21.0 (IBM, Chicago, IL, USA). Figures were generated using GraphPad Prism 5 (La Jolla, CA, USA). The Kolmogorov-Smirnov test was used to check the normality of metric data. Two-group comparisons were performed using the unpaired $t$ test (parametric data) or Mann-Whitney $U$ test (non-parametric data). For pairwise analysis of non-normally distributed data we used Wilcoxon matched pairs test. Multiple comparisons were calculated using one-way analysis of variance (ANOVA) (parametric data) or the Kruskal-Wallis test (non-parametric data) and the appropriate post hoc tests (the Bonferroni and Mann-Whitney $U$ test, respectively). We conducted inclusive logistic regression analyses (maximum likelihood method) to investigate the association between EULAR response or DAS28 $\leq 3.2$ after RTX treatment (dependent variable) and leucocyte count (LC), B cell, T cell, $\mathrm{CD} 4^{+} \mathrm{T}$ cell, $\mathrm{CD} 8^{+} \mathrm{T}$ cell, and natural killer (NK) cell count, and a combined LC and plasmablast score (predictors of primary interest) adjusting for DAS28, current glucocorticoid therapy, disease duration, sex, failure to respond to more than one TNF inhibitor and ACPA status. To identify possible cutoffs for baseline LC and plasmablast frequency distinguishing between EULAR responders and non-responders, receiving operating characteristic (ROC) curves were constructed by plotting sensitivity against one minus specificity varying the cutoffs and calculating the area under the curve (AUC). Data are presented as mean \pm standard error of 
the mean unless indicated otherwise. Odds ratios (OR) are presented with the $95 \%$ confidence interval (CI) in brackets.

\section{Results}

\section{Baseline characteristics}

Because of technical problems, complete data on $\mathrm{T}$ and B cell cytometry was available for only 44 of the 52 patients with RA who were receiving RTX. At week 24, there were 33 patients (75.0 \%) classified as EULAR responders and 15 patients $(34.1 \%)$ had achieved remission or LDA. Baseline characteristics are summarized in Table 1. The baseline characteristics are representative of a typical RA cohort with long-standing RA and high disease activity.

\section{Baseline lymphocyte counts predict EULAR response but not LDA}

We analyzed whether baseline levels of lymphocyte subsets differed between responders and non-responders to RTX therapy. Interestingly, baseline total lymphocyte count (LC) was significantly higher in the non-responder group compared to patients with EULAR response, as depicted in Fig. 1a $(2681 \pm 360 / \mu \mathrm{l}$ and $1956 \pm 124 / \mu \mathrm{l}$, respectively, $P=0.019$ ). We found no significant difference in baseline LC between patients with DAS28 > 3.2 and DAS28 $\leq 3.2$ at week 24 .

Next we investigated if one or more of the lymphocyte subsets were responsible for the negative correlation between EULAR response and cell count. We observed a higher $\mathrm{CD}^{+}$T-cell count in non-responders than in responders $(2022 \pm 904 / \mu \mathrm{l}, 1501 \pm 110 / \mu \mathrm{l}$, respectively, $P=0.040$, Fig. 1b). In addition, non-responders had higher total numbers of $\mathrm{B}$ cells compared to responders ( $421 \pm 92 / \mu \mathrm{l}$ and $185 \pm 18 / \mu \mathrm{l}$, respectively, $P=0.001$, Fig. $1 \mathrm{c}$ ). A detailed analysis of the $\mathrm{B}$ cell subsets in our cohort has already been published [11]. Among the T-cell subsets we found higher levels of $\mathrm{CD} 4^{+} \mathrm{T}$ cells in the non-responder group $(1504 \pm 205 / \mu \mathrm{l}$ and $1047 \pm 84 / \mu \mathrm{l}$, respectively, $P=$ 0.19; Fig. 1d). Importantly, at baseline none of these populations was significantly different between patients with a DAS28 $>3.2$ or a DAS28 $\leq 3.2$ at week 24 . This was also true for the plasmablast frequency, a predictor of EULAR response identified previously [11]. Furthermore, we did not detect any significant difference in the prevalence of $\mathrm{CD} 8^{+} \mathrm{T}$ cells and natural killer cells (data not shown). In addition, DMARD therapy and glucocorticoid use had no influence on lymphocyte counts or lymphocyte subsets (Additional file 1: Table S1). In univariate logistic regression analysis high baseline LC, B cell, T cell, and $\mathrm{CD} 4^{+} \mathrm{T}$ cell counts were negative predictors of EULAR response but there were no predictors of LDA (Table 2).

Multivariate regression analysis as described in Methods was then carried out to adjust the data for possible confounders, confirming the results from univariate analysis: $\mathrm{LC}$, T cell, B cell, and CD4 ${ }^{+} \mathrm{T}$ cell counts were independent negative predictors of EULAR response (Table 3).

\section{Combining baseline LC and plasmablast frequency predicts low disease activity}

The current focus in RA therapy is to achieve remission or LDA by 6 months [12]. None of the cellular biomarkers evaluated so far solely predicted LDA. Therefore, we investigated whether a combination of two biomarkers could be used for predicting LDA. We hypothesized that these biomarkers would have to identify a different patient group each, in order to improve the prediction. By blotting each of the candidate biomarkers against each other, we found that high LC and high plasmablasts, a predictor of EULAR response identified previously [11], each recognized a different population of patients not reaching LDA by week 24 (Fig. 2a). In contrast, all patients who did reach LDA had low LC and low plasmablast frequency (Fig. 2b). This finding prompted us to use a combination of both biomarkers in inclusive disjunction. The cutoffs for both values were chosen to yield at least $90 \%$

Table 1 Baseline characteristics of patients included in the study

\begin{tabular}{|c|c|c|c|c|c|c|}
\hline Parameter & $\begin{array}{l}\text { Non-responders } \\
(n=11)\end{array}$ & $\begin{array}{l}\text { Responders } \\
(n=33)\end{array}$ & $\begin{array}{l}P \\
\text { value }\end{array}$ & $\begin{array}{l}\text { DAS28 > } 3.2(\text { week 24) } \\
(n=29)\end{array}$ & $\begin{array}{l}\text { DAS28 } \leq 3.2(\text { week } 24) \\
(n=15)\end{array}$ & $\begin{array}{l}P \\
\text { value }\end{array}$ \\
\hline Age in years (mean $\pm S D$ ) & $58.9 \pm 10.8$ & $62.5 \pm 13.3$ & 0.423 & $61.8 \pm 13.8$ & $61.3 \pm 10.7$ & 0.898 \\
\hline Female gender, $\%$ & 72 & 81 & 0.640 & 76 & 87 & 0.411 \\
\hline Disease duration in years (mean $\pm \mathrm{SD}$ ) & $15.1 \pm 12.7$ & $12.9 \pm 8.8$ & 0.536 & $12.7 \pm 10.5$ & $15.4 \pm 8.1$ & 0.428 \\
\hline DAS28-ESR (mean \pm SD) & $5.0 \pm 1.1$ & $6.0 \pm 1.1$ & 0.008 & $5.8 \pm 1.1$ & $5.7 \pm 1.3$ & 0.753 \\
\hline RF-positive, \% & 100 & 87 & 0.236 & 86 & 100 & 0.138 \\
\hline ACPA-positive, $\%$ & 78 & 76 & 0.909 & 72 & 85 & 0.399 \\
\hline Corticosteroids, \% & 36 & 30 & 0.061 & 34 & 26 & 0.608 \\
\hline Previous TNF inhibitors (mean \pm SD) & $1.7 \pm 1.2$ & $1.2 \pm 0.9$ & 0.194 & $1.5 \pm 1.1$ & $1.2 \pm 0.7$ & 0.346 \\
\hline
\end{tabular}

Significant $P$ values are indicated in bold numbers

DAS28 disease activity score in 28 joints, $S D$ standard deviation, ESR erythrocyte sedimentation rate, $R F$ rheumatoid factor lgM, $A C P A$ anti-citrullinated peptide antibody, TNF tumor necrosis factor 

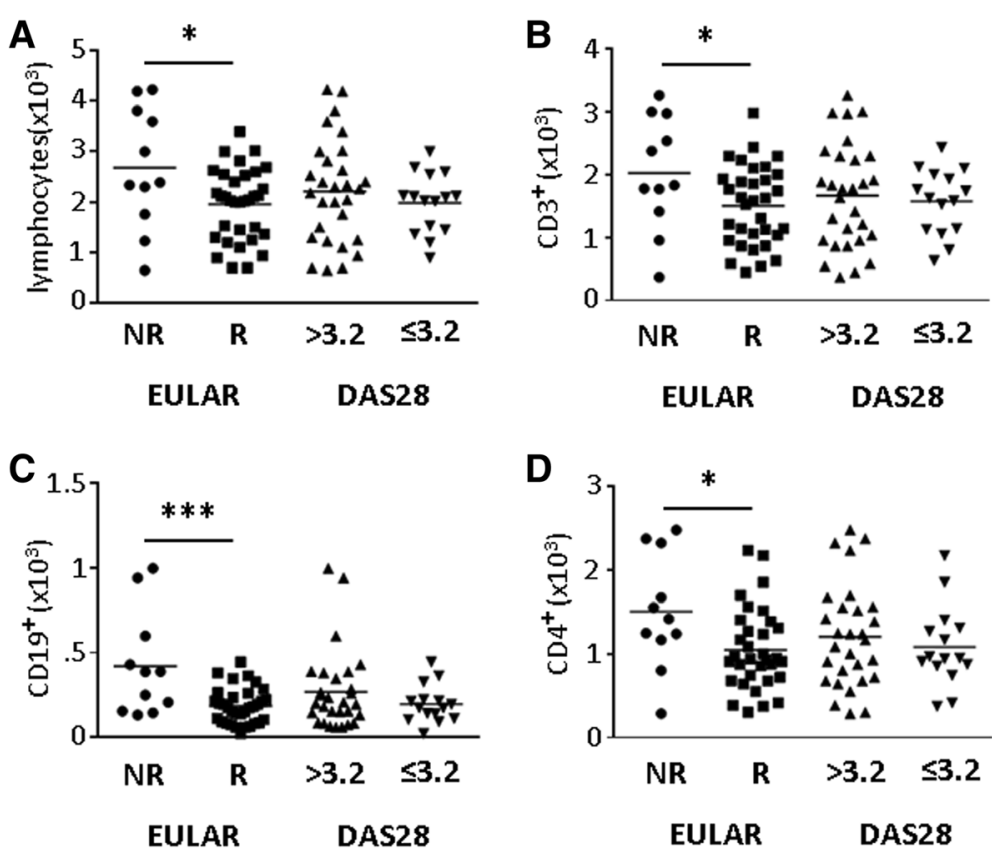

Fig. 1 Rituximab (RTX) non-responders (NR) have higher baseline lymphocyte, T cell, and CD4 ${ }^{+}$lymphocyte counts than responders (R). Lymphocyte (a), $\mathrm{CD}_{4} 5^{+} \mathrm{CD}^{+}$(b), $\mathrm{CD} 45^{+} \mathrm{CD} 19^{+}$(c), and $\mathrm{CD} 45^{+} \mathrm{CD}^{+} \mathrm{CD}^{+}$(d) counts were obtained before treatment with RTX. European League Against Rheumatism (EULAR) response and disease activity score in 28 joints (DAS28) were assessed at week 24 after treatment with RTX. Data are presented as cells/ $\mu$ l. Each dot represents a patient; horizontal bars indicate the mean. Statistical significance was assessed using the Mann-Whitney $U$ test. ${ }^{*} P<0.05,{ }^{* * *} P<0.001$

specificity for non-response generated by ROC analysis (Additional file 2: Figure S1). Patients with elevated LC $>2910 / \mu$ l or plasmablast frequency $>2.85 \%$ (hiLOP) at baseline had a significantly higher DAS28 at week 24 after treatment with RTX than patients who had LC and plasmablast frequency below the thresholds (loLAP) (DAS28 of $4.9 \pm 0.3$ and $3.7 \pm 0.2$, respectively; $P=0.002$. Fig. 2 c). Positive and negative predictive values for achieving a DAS28 $\leq 3.2$ are given in Table 4 .

To test if hiLOP was an independent predictor of a DAS28 $\leq 3.2$ we performed multivariate regression

Table 2 Univariate logistic regression models predicting EULAR response and DAS28 $\leq 3.2$ at week 24 after rituximab

\begin{tabular}{|c|c|c|c|c|}
\hline \multirow[t]{2}{*}{ Baseline variables } & \multicolumn{2}{|l|}{ EULAR response } & \multicolumn{2}{|l|}{ DAS28 $\leq 3.2$} \\
\hline & OR $(95 \%$ Cl) & $P$ value & OR $(95 \% \mathrm{Cl})$ & $P$ value \\
\hline Leucocyles & $1.00(1.00-1.00)$ & 0.926 & $1.00(1.00-1.00)$ & 0.892 \\
\hline $\mathrm{LC}^{\mathrm{a}}$ & $0.91(0.83-0.99)$ & 0.030 & $0.97(0.90-1$ & 0.420 \\
\hline Natural killer cells ${ }^{a}$ & $0.93(0.59-1.48)$ & 0.766 & $0.85(0.50-1.41)$ & 0.524 \\
\hline $\mathrm{B}$ cells ${ }^{\mathrm{a}}$ & $0.48(0.26-0.87)$ & 0.015 & $0.79(0.52-1.20)$ & 0.274 \\
\hline $\mathrm{T}$ cells ${ }^{\mathrm{a}}$ & $0.90(0.81-1.00)$ & 0.050 & $0.98(0.91-1.07)$ & 0.692 \\
\hline $\mathrm{CD}^{+\mathrm{a}}$ & $0.87(0.76-0.99)$ & 0.029 & $0.96(0.86-1.08)$ & 0.491 \\
\hline $\mathrm{CD} 8^{+\mathrm{a}}$ & $0.94(0.74-1.20)$ & 0.607 & $1.061(0.85-1.33)$ & 0.640 \\
\hline
\end{tabular}

${ }^{a}$ Absolute values, multiplied by 100. EULAR European League Against Rheumatism, DAS28 disease activity score in 28 joints, $C l$ confidence interval, $L C$ total lymphocyte count, $O R$ odds ratio (indicated per 100 cells $/ \mu$ increase) Significant $P$ values are indicated in bold numbers corrected for possible confounders. Indeed, baseline hiLOP significantly and independently predicted that patients treated with RTX would not reach DAS28 $\leq 3.2$ at week 24 (OR 0.11, $95 \%$ CI $0.01-0.89, P=0.037$ ). In contrast, other combinations of LC, plasmablast frequency, T cell, $\mathrm{B}$ cell, or $\mathrm{CD}^{+} \mathrm{T}$ cell counts were not predictive of a DAS28 $\leq 3.2$ in our analysis (data not shown).

T cell numbers are reduced after treatment with RTX but do not correlate with clinical response

We also tested whether a change in the absolute $\mathrm{T}$ cell count after therapy with RTX correlates with EULAR response as reported previously [14, 20]. The absolute number of T lymphocytes at week 24 after RTX was reduced to $79.9 \%$ of baseline levels $(1652 \pm 113 / \mu l$ to

Table 3 Multivariate logistic regression models predicting EULAR response at week 24 after rituximab

\begin{tabular}{llc}
\hline $\begin{array}{l}\text { Baseline } \\
\text { variables }\end{array}$ & EULAR response & \\
\cline { 2 - 3 } & OR $(95 \% \mathrm{Cl})$ & $P$ value \\
\hline LC $^{\mathrm{a}}$ & $0.88(0.80-0.89)$ & 0.021 \\
$\mathrm{~B}$ cells $^{\mathrm{a}}$ & $0.43(0.22-0.88)$ & 0.020 \\
$\mathrm{~T}_{\text {cells }}{ }^{\mathrm{a}}$ & $0.87(0.70-0.96)$ & 0.018 \\
$\mathrm{CD}^{+}{ }^{\mathrm{a}}$ & $0.82(0.70-0.97)$ & 0.015 \\
\hline
\end{tabular}

${ }^{a}$ Absolute values, multiplied by 100. EULAR European League Against Rheumatism, $C l$ confidence interval, $L C$ total lymphocyte count, $O R$ odds ratio (indicated per $100 \mathrm{cells} / \mu \mathrm{l}$ increase) 

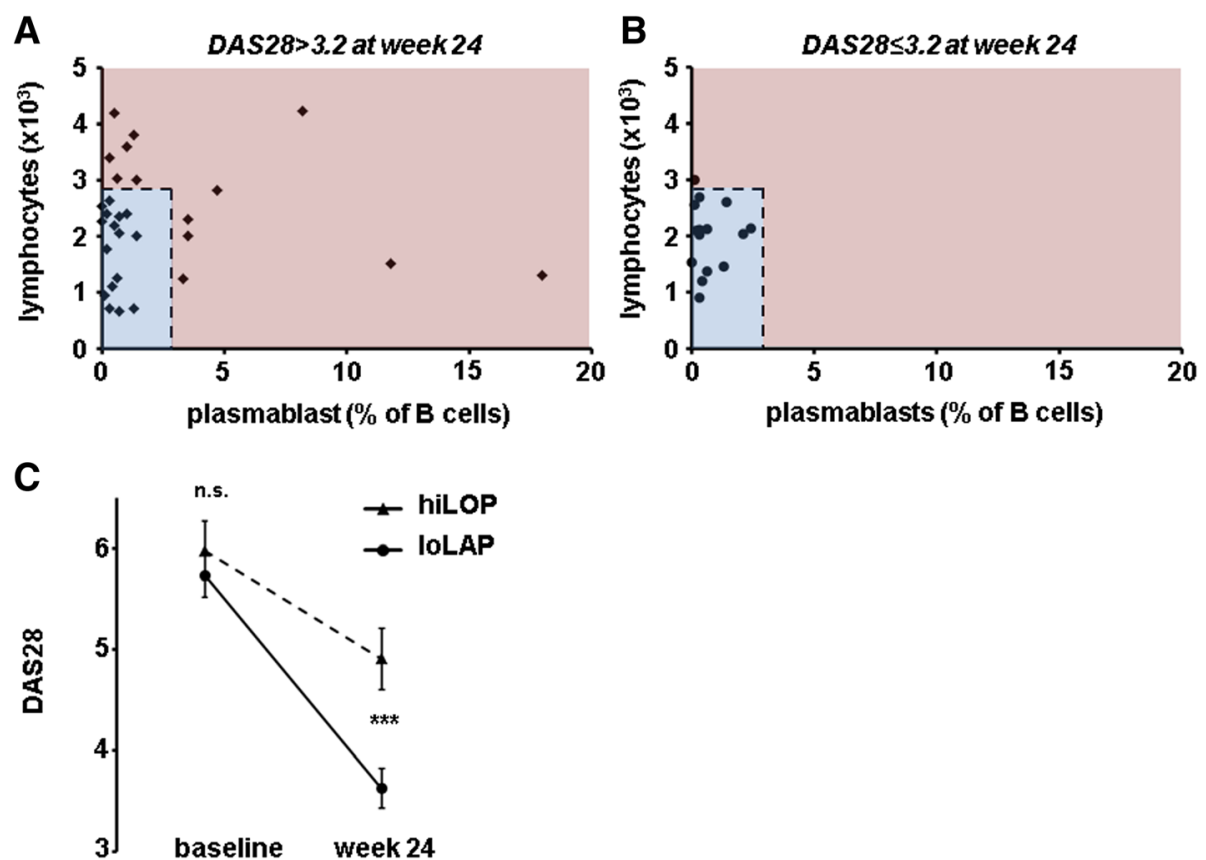

Fig. 2 Patients with high total lymphocyte counts (LC) or high frequency of plasmablasts (hiLOP) have higher disease activity. Baseline values of LC and plasmablasts in patients not achieving low disease activity (LDA) after 24 weeks (a). Baseline values of LC and plasmablasts in patients achieving LDA after 24 weeks (b). Dotted lines indicate the cutoff for baseline. Red and blue indicate the area for baseline hiLOP or low number of total lymphocyte counts and plasmablasts (IoLAP), respectively. Change in disease activity score in 28 joints (DAS28) in patients with baseline loLAP and hiLOP (c). Statistical significance was assessed using the Mann-Whitney $U$ test; ${ }^{* * *} P<0.001$

$1320 \pm 88 / \mu \mathrm{l}, P=0.003$, Fig. 3a). We also found a reduction of $\mathrm{CD}^{+} \mathrm{T}$ lymphocytes $(1174 \pm 88 / \mu \mathrm{l}$ to $933 \pm 60 / \mu \mathrm{l}$, $P=0.007$, Fig. 3b), CD8 ${ }^{+} \mathrm{T}$ lymphocytes $(492 \pm 44 / \mu \mathrm{l}$ to $399 \pm 45 / \mu \mathrm{l}, P=0.001)$ but not natural killer cell numbers $(242 \pm 24 / \mu \mathrm{l}$ to $229 \pm 24 / \mu \mathrm{l}, P=0.475)$ by flow cytometry. However, neither the reduction of $\mathrm{T}$ lymphocytes nor the decrement of $\mathrm{CD}_{4}^{+}$T-cell levels was associated with a EULAR response or a DAS2 $8 \leq 3.2$ as outlined in Fig. $3 c$ and $d(P>0.05)$. Changes within the $\mathrm{CD}^{+} \mathrm{T}$ lymphocyte subset were also similar in responders and non-responders (data not shown).

\section{Discussion}

Selection of a new DMARD for patients with RA who are responding insufficiently to a current therapy is a delicate decision. Currently the best predictor of reaching remission or LDA is not an individual biomarker,

Table 4 Contingency table of loLAP or hiLOP scores and disease activity at week 24

\begin{tabular}{llll}
\hline & lOLAP & hiLOP & \\
\hline DAS28 $\leq 3.2$ & 14 & 1 & Sensitivity: $93.3 \%$ \\
DAS28 $>3.2$ & 16 & 13 & Specificity: $44.8 \%$ \\
& PPV: $46.7 \%$ & NPV: $92.9 \%$ & \\
\hline
\end{tabular}

hiLOP high number of total lymphocyte count or plasmablasts, IoLAP low number of total lymphocyte count and plasmablasts, DAS28 disease activity score in 28 joints; PPV positive predictive value, NPV negative predictive value but the level of disease activity and its reduction, especially during the first 3 months of treatment [21].

Measurement of the LC is simple and cheap. In our study $91 \%$ of responders had LC below the cutoff of $<2910$ lymphocytes/ $\mu$ l. Interestingly, this value is higher than that reported by Ferraccioli et al. [3], who found that a lymphocyte count below $1875 / \mu \mathrm{l}$ is an excellent predictor of a good EULAR response following B cell depletion. The difference between cutoff values may be related to differences in the two RA cohorts: our patients had higher disease activity (5.8 versus 4.6), fewer of them took glucocorticoids (30\% versus $80 \%$ ), and all were RF-IgM-positive (100\% versus $85 \%$ ).

As LC characterized a different population of nonresponders compared to high levels of plasmablasts, we combined the baseline values of LC and plasmablast frequency and generated an LOP score that has high negative predictive value and sensitivity to identify patients who will not achieve low disease activity under RTX. This is especially important for treatment decisions in clinical practice, where the target of treatment is remission or at least low disease activity [12]. Our data suggest that LC and B cell subtyping should be performed in patients before treatment decisions. Treatment options other than RTX may be preferred for patients who have hiLOP. 

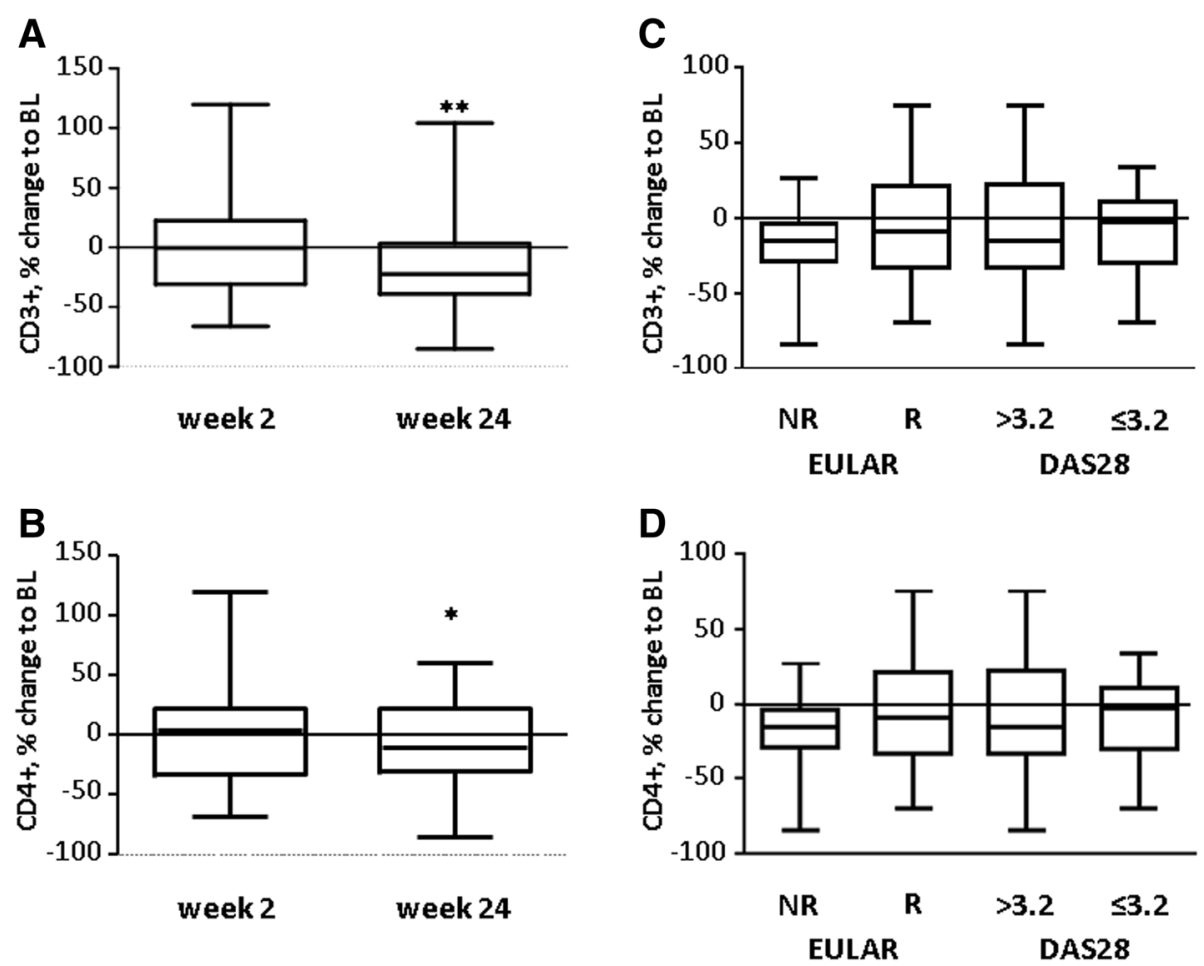

Fig. $3 \mathrm{~T}$ cell numbers are reduced after treatment with rituximab (RTX) but do not correlate with clinical response. $\mathrm{CD} 45^{+} \mathrm{CD} 3^{+}(\mathbf{a}, \mathbf{c})$ and $\mathrm{CD} 45^{+} \mathrm{CD}^{+} \mathrm{CD}^{+}$(b, d) lymphocytes of all patients were analyzed at the indicated time points after treatment with RTX (a, b) or at week 24, separated according to European League Against Rheumatism (EULAR) response and disease activity in 28 joints (DAS28) at week 24 (c, d). Data are presented as percentage change of the indicated lymphocyte subset compared to baseline (BL). Boxes represent the median, with $50 \%$ of cases within the boxes. Whiskers represent the minimum and maximum. Statistical significance was assessed using the Wilcoxon matched pairs test $(\mathbf{a}, \mathbf{b})$ and one-way analysis of variance $(\mathbf{c}, \mathbf{d}) ;{ }^{*} P<0.05,{ }^{*} P<0.01$. $R$ responders, NR non-responders

We observed a decrease in $\mathrm{T}$ cell numbers 24 weeks after treatment with RTX. In line with our findings, in two recent studies there was also a reduction in circulating $\mathrm{T}$ cells in patients treated with RTX $[14,20]$. Intriguingly, the reduction in overall T cells after RTX in these studies correlated with EULAR response, which we did not confirm in our cohort. Again, differences in patient characteristics may account for the divergent findings, as more of our patients were RF-positive and fewer were taking steroids.

How RTX might affect T cell homeostasis is still under discussion. One possibility could be a direct effect on $\mathrm{CD} 20^{+} \mathrm{T}$ cells. This has recently been demonstrated in patients with multiple sclerosis [22], but it seems unlikely in RA because of the small number of peripheral $T$ cells expressing this molecule as Melet et al. have indicated [14]. Evidence for an indirect effect of RTX comes from observations in lupus-prone MRL-lpr/lpr mice. Analysis of B-cell-intact and B-cell-deficient mice demonstrates that the expansion of activated and memory $\mathrm{T}$ cells is highly dependent on the presence of B cells [23]. Furthermore, B cell depletion limits the generation of $\mathrm{CD} 4+$ memory $\mathrm{T}$ cells and reduces protection against disseminating virus infection [24]. Thus, diminishing the number of B cells reduces signals for the activation and expansion of $\mathrm{T}$ cells. In line with this are reports of a diminished number of activated $\mathrm{CD} 69^{+}$or $\mathrm{CD} 154^{+} \mathrm{T}$ cells after successful B cell depletion therapy in humans with systemic lupus erythematosus $[25,26]$.

How low numbers of total lymphocytes may be beneficial for patients with RA treated with RTX is unknown. Approximately $75 \%$ of total lymphocytes are T cells and $60 \%$ of these are $\mathrm{CD} 4^{+}$[27]. Within this population are helper cells that are able to promote the survival of autoreactive B cells [28]. Starting with a low number of $\mathrm{T}$ lymphocytes the additional decrease in these cells after RTX might be sufficient to disrupt the reciprocal activation of auto-reactive $\mathrm{T}$ and $\mathrm{B}$ cells.

A limitation of our study is the small sample size and the lack of detailed characterization of $\mathrm{T}$ cells. In addition, as all our patients were RF-positive it was not possible to meaningfully assess any statistical association between autoantibodies and EULAR response. ACPA status, however, was neither linked with EULAR response nor confounded the predictive values of $\mathrm{LC}, \mathrm{CD} 4^{+} \mathrm{T}$ lymphocyte count, or hiLOP outcome. 
Whether patients with high LC or plasmablast frequency would benefit from an additional cycle of rituximab as suggested by Vital et al. [8] cannot be answered by our study. As a first step we would like to confirm our data in a prospective clinical trial selecting patients with RA for RTX therapy according to their LOP score.

\section{Conclusions}

Currently, there are several bDMARDs available for the treatment of RA, but despite a plethora of data from different studies no single biomarker has emerged that might predict the response to different therapies. Here we describe a combination of biomarkers, i.e., high LC and plasmablast frequency at baseline, that reliably identify patients who are likely to fail to respond to RTX treatment.

\section{Additional files}

Additional file 1: Table S1. One-way ANOVA for leucocyte subsets and treatment. (DOCX $17 \mathrm{~kb}$ )

Additional file 2: Figure S1. ROC curves of $L C$ and $C D 4^{+}$lymphocyte counts. Sensitivity for EULAR response blotted against false negative rate (1-specificity), at various threshold settings for baseline $L C$ and $C D 45^{+} C D 3$ ${ }^{+} \mathrm{CD} 4^{+}$counts. The increasing area under the curve (AUC) corresponds to higher diagnostic accuracy. (TIFF $42 \mathrm{~kb}$ )

\section{Acknowledgements}

We thank Verena Krischan and Irene Holzer for technical assistance and Saelde Baumgartner and Barbara Nussbaumer for logistic support.

\section{Funding}

This work was supported by an unrestricted grant from Roche (Vienna, Austria). The funder had no role in study design, data collection and analysis, decision to publish, or preparation of the manuscript.

\section{Availability of supporting data}

Data can be requested from the corresponding author.

\section{Authors' contributions}

MHS made a substantial contribution to study conception and design, and to data acquisition, analysis and interpretation. CD and KB were involved in the study conception, coordination, design, and data acquisition. WG made substantial contributions to analysis and interpretation of data. HPB made a substantial contribution to study conception, design, and data acquisition. $M H S$ and $\mathrm{HPB}$ wrote the first version of the manuscript and $M H S, C D, K B$, WBG, and $\mathrm{HPB}$ revised it critically. MHS, CD, KB, WBG, and $\mathrm{HPB}$ read and approved the final manuscript.

\section{Competing interests}

The authors declare that they have no competing interests.

\section{Consent for publication}

Not applicable

\section{Ethical approval and consent to participate}

Written informed consent was obtained from each patient before entering the study, in accordance with the protocol approved by the institutional review board of the Medical University Graz.

Received: 14 May 2016 Accepted: 8 August 2016

Published online: 24 August 2016

\section{References}

1. Scott DL. Biologics-based therapy for the treatment of rheumatoid arthritis. Clin Pharmacol Ther. 2012;91(1):30-43.

2. Cohen SB, Emery P, Greenwald MW, et al. Rituximab for rheumatoid arthritis refractory to anti-tumor necrosis factor therapy: Results of a multicenter, randomized, double-blind, placebo-controlled, phase III trial evaluating primary efficacy and safety at twenty-four weeks. Arthritis Rheum. 2006; 54(9):2793-806

3. Ferraccioli G, Tolusso B, Bobbio-Pallavicini F, et al. Biomarkers of good EULAR response to the $B$ cell depletion therapy in all seropositive rheumatoid arthritis patients: clues for the pathogenesis. PLoS One. 2012; 7(7):e40362.

4. Quartuccio L, Fabris M, Salvin S, et al. Rheumatoid factor positivity rather than anti-CCP positivity, a lower disability and a lower number of anti-TNF agents failed are associated with response to rituximab in rheumatoid arthritis. Rheumatology (Oxford). 2009;48(12):1557-9.

5. Chatzidionysiou K, Lie E, Nasonov E, et al. Highest clinical effectiveness of rituximab in autoantibody-positive patients with rheumatoid arthritis and in those for whom no more than one previous TNF antagonist has failed: pooled data from 10 European registries. Ann Rheum Dis. 2011;70(9):1575-80.

6. Choi IY, Gerlag DM, Herenius MJ, et al. MRP8/14 serum levels as a strong predictor of response to biological treatments in patients with rheumatoid arthritis. Ann Rheum Dis. 2015;74(3):499-505.

7. Dass S, Rawstron AC, Vital EM, et al. Highly sensitive B cell analysis predicts response to rituximab therapy in rheumatoid arthritis. Arthritis Rheum. 2008:58(10):2993-9.

8. Vital EM, Dass S, Rawstron AC, et al. Management of nonresponse to rituximab in rheumatoid arthritis: predictors and outcome of re-treatment Arthritis Rheum. 2010;62(5):1273-9.

9. Vital EM, Rawstron AC, Dass $S$, et al. Reduced-dose rituximab in rheumatoid arthritis: efficacy depends on degree of B cell depletion. Arthritis Rheum. 2011;63(3):603-8.

10. Owczarczyk K, Lal P, Abbas AR, et al. A plasmablast biomarker for nonresponse to antibody therapy to CD20 in rheumatoid arthritis. Sci Trans Med. 2011;3(101):101ra92.

11. Brezinschek HP, Rainer F, Brickmann K, et al. B lymphocyte-typing for prediction of clinical response to rituximab. Arthritis Res Ther. 2012;14(4):R161.

12. Smolen JS, Landewe R, Breedveld FC, et al. EULAR recommendations for the management of rheumatoid arthritis with synthetic and biological disease-modifying antirheumatic drugs: 2013 update. Ann Rheum Dis. 2014;73(3):492-509.

13. McInnes IB, Schett $\mathrm{G}$. The pathogenesis of rheumatoid arthritis. N Engl J Med. 2011:365(23):2205-19.

14. Melet J, Mulleman D, Goupille P, et al. Rituximab-induced T cell depletion in patients with rheumatoid arthritis: association with clinical response. Arthritis Rheum. 2013;65(11):2783-90.

15. Feuchtenberger $M$, Muller $S$, Roll $P$, et al. Frequency of regulatory $T$ cells is not affected by transient $\mathrm{B}$ cell depletion using anti-CD20 antibodies in rheumatoid arthritis. Open Rheumatol J. 2008:2:81-8.

16. Thurlings RM, Vos K, Wijbrandts CA, et al. Synovial tissue response to rituximab: mechanism of action and identification of biomarkers of response. Ann Rheum Dis. 2008;67(7):917-25.

17. Arnett FC, Edworthy SM, Bloch DA, et al. The American Rheumatism Association 1987 revised criteria for the classification of rheumatoid arthritis. Arthritis Rheum. 1988:31(3):315-24

18. van Gestel AM, Prevoo ML, van 't Hof MA, et al. Development and validation of the European League Against Rheumatism response criteria for rheumatoid arthritis. Comparison with the preliminary American College of Rheumatology and the World Health Organization/International League Against Rheumatism Criteria. Arthritis Rheum. 1996;39(1):34-40.

19. Wells G, Becker JC, Teng J, et al. Validation of the 28-joint Disease Activity Score (DAS28) and European League Against Rheumatism response criteria based on C-reactive protein against disease progression in patients with rheumatoid arthritis, and comparison with the DAS28 based on erythrocyte sedimentation rate. Ann Rheum Dis. 2009;68(6):954-60.

20. Piantoni S, Scarsi M, Tincani A, et al. Circulating CD4+ T-cell number decreases in rheumatoid patients with clinical response to rituximab. Rheumatol Int. 2015:35(9):1571-3.

21. Aletaha D, Funovits J, Keystone EC, et al. Disease activity early in the course of treatment predicts response to therapy after one year in rheumatoid arthritis patients. Arthritis Rheum. 2007;56(10):3226-35. 
22. Palanichamy A, Jahn S, Nickles D, et al. Rituximab efficiently depletes increased CD20-expressing T cells in multiple sclerosis patients. J Immunol. 2014;193(2):580-6.

23. Chan O, Shlomchik MJ. A new role for B cells in systemic autoimmunity: B cells promote spontaneous T cell activation in MRL-Ipr/lpr mice. J Immunol. 1998;160(1):51-9.

24. Misumi I, Whitmire JK. B cell depletion curtails CD4+ T cell memory and reduces protection against disseminating virus infection. J Immunol. 2014;192(4):1597-608.

25. Sfikakis PP, Boletis JN, Lionaki S, et al. Remission of proliferative lupus nephritis following B cell depletion therapy is preceded by down-regulation of the T cell costimulatory molecule CD40 ligand: an open-label trial. Arthritis Rheum. 2005;52(2):501-13.

26. Tokunaga M, Saito K, Kawabata D, et al. Efficacy of rituximab (anti-CD20) for refractory systemic lupus erythematosus involving the central nervous system. Ann Rheum Dis. 2007;66(4):470-5.

27. Santagostino A, Garbaccio G, Pistorio A, et al. An Italian national multicenter study for the definition of reference ranges for normal values of peripheral blood lymphocyte subsets in healthy adults. Haematologica. 1999;84(6):499-504.

28. Lesley R, Kelly LM, Xu Y, et al. Naive CD4 T cells constitutively express CD40L and augment autoreactive B cell survival. Proc Natl Acad Sci U S A. 2006:103(28):10717-22

\section{Submit your next manuscript to BioMed Central} and we will help you at every step:

- We accept pre-submission inquiries

- Our selector tool helps you to find the most relevant journal

- We provide round the clock customer support

- Convenient online submission

- Thorough peer review

- Inclusion in PubMed and all major indexing services

- Maximum visibility for your research

Submit your manuscript at www.biomedcentral.com/submit 